\title{
Resistencia a la corrosión en ambiente salino de un acero al carbono recubierto con aluminio por rociado térmico y pintura poli aspártica
}

\section{Corrosion resistance in saline environment of a carbon steel coated with aluminum by thermal spray and painting poly aspartic}

\section{Resistência à corrosão em um ambiente salino aço carbono revestido com alumínio por aspersão térmica e pintura poli aspártica}

\author{
José Luddey Marulanda Arévalo1*; Diego Pérez-Muñoz¹; Aduljay Remolina Millan² \\ ${ }^{1}$ Facultad de ingeniería mecánica- Universidad Tecnológica de Pereira (UTP). La julita. Pereira-Colombia \\ ${ }^{2}$ Facultad de ingeniería mecánica- Universidad Pontificia Bolivariana (UPB). Km 7 vía Piedecuesta. Bucaramanga- \\ Colombia \\ *jlmarulanda@utp.edu.co
}

Fecha Recepción: 18 de julio de 2016 Fecha Aceptación: 14 de septiembre de 2016

\begin{abstract}
Resumen
Se evaluó la resistencia a la corrosión en ambiente salino del acero 1020 recubierto con aluminio por medio de rociado térmico por arco eléctrico y después se aplicó una pintura poliaspártica. Se observó que este sistema presenta una protección en estos ambientes, reduciendo la velocidad de corrosión, en comparación con un sistema de pintura bicapa, el cual consistía en una capa rica en zinc y otra capa de pintura poliaspártica. Se realizó la caracterización del recubrimiento por medio de Microscopía Electrónica de Barrido (MEB) para analizar su comportamiento con respecto al sustrato y a la pintura para conocer variaciones en propiedades como adherencia, topografía y homogeneidad. Se observó que las probetas recubiertas con aluminio por rociado térmico presentan una mayor resistencia a la corrosión en cámara salina que las probetas que no fueron recubiertas y solo estaban protegidas por el sistema bicapa de pintura, aunque la pintura sin rociado térmico tuvo un buen desempeño ya que no falló durante el tiempo estipulado para en ensayo en cámara de niebla salina.
\end{abstract}

Palabras clave: aluminio, corrosión, niebla salina, pintura, rociado térmico.

\begin{abstract}
The corrosion resistance was assessed in saline environment on a 1020 steel coated with aluminum by arc thermal spraying and then a polyaspartic paint was applied. It was observed that this system has a protection in these environments, reducing the corrosion rate, compared to a bilayer paint system, which consisted of zinc-rich paint layer and polyaspartic coating. Coating characterization was performed by SEM to analyze their behavior with respect to the substrate and paint to meet variations in properties such as adhesion, homogeneity and topography. It was observed that the samples coated with aluminum by thermal spraying showed good corrosion resistance in salt spray the specimens that were not coated, just were protected by the bilayer coating system, even the paint without thermal spraying performed well and that did not fail during the time stipulated in test for salt spray.
\end{abstract}

Keywords: aluminum, corrosion, paint, salt spray, thermal spray.

Cita: Marulanda JL, Pérez-Muñoz D, Remolina Millan A. Resistencia a la corrosión en ambiente salino de un acero al carbono recubierto con aluminio por rociado térmico y pintura poli aspártica. rev.ion. 2017;30(1):21-31. 


\section{Resumo}

A resistência à corrosão em solução salina ambiente 1020 aço revestido com alumínio por aspersão térmica de arco foi avaliado e, em seguida, foi aplicada uma tinta poli aspártico. Observou-se que este sistema tem uma proteç̧ão nestes ambientes, reduzindo a taxa de corrosão, em comparação com um sistema de pintura de duas camadas, que consistia de um fardo rico em zinco, e outra camada de tinta poliaspártica. Revestimento caracterização foi realizada por SEM para analisar o seu comportamento em relação ao substrato e a tinta para satisfazer as variações nas propriedades de adesão, tais como, a uniformidade e a topografia. Observou-se que as amostras revestidas com alumínio por aspersão térmica apresentam uma maior resistência à corrosão em sal pulverizar as amostras que não foram revestidas sozinho foram protegidas pelo sistema de revestimento de duas camadas, embora bem a tinta sem pulverização térmica e realizada ele não falhou durante o tempo estipulado para ser testado em névoa salina.

Palabras-chave: alumínio, aspersão térmica, corrosão, salt spray, tintas.

\section{Introducción}

La protección del acero contra la degradación por corrosión o desgaste es muy importante para reducir los costos mediante la preservación de la estructura y aumentar su vida útil. El acero estructural tiene baja resistencia a la corrosión salina y se necesita protegerlos por medio de tratamientos superficiales a través de recubrimientos con otros materiales tales como metales, cerámicos o polímeros. Los recubrimientos tienen como función la protección de las estructuras de acero mediante la prevención de su contacto con el medio corrosivo, a través de lo que se conoce como protección de barrera, siendo el aluminio y sus aleaciones muy utilizados debido a su buena resistencia a la corrosión, en particular en ambiente húmedo donde se forma una capa hidratada $\left(\mathrm{Al}_{2} \mathrm{O}_{3} 3 \mathrm{H}_{2} \mathrm{O}\right)$, que mejora la resistencia a la oxidación del metal [1,2]. Para producir este tipo de revestimientos de aluminio sobre sustratos de acero se puede realizar por Deposición Física de Vapor (PVD), Deposición Asistida por Haz de lones (IBAD), Deposición Química de Vapor (CVD) y rociado térmico, entre otros. La ventaja del rociado térmico es que se pueden obtener revestimientos más gruesos (cientos de micras), para la protección contra la corrosión en ambientes salinos o marinos [3-6].

El rociado térmico es un proceso para añadir a un metal capas del mismo material o de otros metales, donde la combinación resultante puede tener mejores propiedades físicas, mecánicas, químicas o costos más económicos que el material uniforme. [7-9]. En la industria, numerosas piezas se ven sometidas a grandes esfuerzos con diferentes tipos de desgastes como la corrosión, lo que genera pérdidas considerables, las cuales podrían ser reducidas gracias a la técnica de rociado térmico por arco eléctrico, proporcionando así, un impacto importante en la productividad, ya que el rociado térmico por arco es conocido por ser una de las técnicas menos costosas del rociado térmico $[10,11]$.

Los metales rociados térmicamente han demostrado producir una mayor vida útil al acero que el sistema de pintura. El aluminio puede ser dejado a una exposición corrosiva abierta y a pesar de ello, resistir más al desgaste corrosivo. Uno de los beneficios obtenidos es que el recubrimiento puede ser utilizado casi inmediatamente después de ser aplicado, inclusive puede ser aplicado en zonas parciales (por ejemplo, cuando se están haciendo reparaciones con soldadura), sin tener que esperar como en la pintura tradicional. El aluminio rociado térmicamente trabaja muy bien en ambientes con elevada temperatura, inclusive por encima de los $120^{\circ} \mathrm{C}$. El rociado térmico con aluminio protege al acero contra la corrosión alcalina hasta el más severo nivel, comparativamente con los recubrimientos orgánicos, ofrece un mayor costo/beneficio por la larga vida de duración de los recubrimientos rociados térmicamente [12-14]. La tecnología de pinturas ricas en zinc ha sido utilizada durante años, para la protección de estructuras en ambientes agresivos como los industriales y marinos entre otros. Este sistema de recubrimiento puede constar de una capa rica en zinc y una capa de acabado poliaspártica. Los pigmentos de sacrificio de zinc, requieren de grandes cantidades, con el fin de permitir el flujo de corriente eléctrica. En la etapa inicial de protección de esta pintura; el zinc debe estar en contacto eléctrico con la superficie de acero para que realice el papel de 
ánodo de sacrificio, proporcionando protección catódica. En etapas posteriores los productos de corrosión del zinc como óxidos y/o hidróxidos de zinc, forman una barrera de protección. El alto contenido de pigmentos de zinc puede dar lugar a malas propiedades mecánicas del recubrimiento y provocar problemas de homogeneidad en el recubrimiento seco. También se sabe que una fracción significativa de zinc no se utiliza durante la vida de revestimiento debido a su corrosión [15-16].

\section{Procedimiento experimental}

Se fabricaron 20 probetas de un acero de bajo carbono de dimensiones $(10 \mathrm{~cm} \times 20 \mathrm{~cm})$, que fueron sometidas a un proceso de granallado (shot blasting) para proporcionarle rugosidad a la superficie de las probetas y tener un buen perfil de anclaje para obtener una buena adherencia del rociado térmico y de las pinturas. El granallado fue realizado por la empresa ABB Transformadores, con granalla esférica de durezas entre 40 y $51 \mathrm{HRC}$ y con una presión de 110psi. A 10 de las 20 probetas, se aplicó una pintura bicapa, que consta de una capa imprimante epóxico rico en zinc y otra capa de pintura poliaspártica de presentación. A las 10 probetas restantes se les depositó un recubrimiento de aluminio por rociado térmico por arco eléctrico, este proceso se llevó a cabo a una presión de $55 p s i$ y a una distancia de $(20-30) \mathrm{cm}$, el alambre fue de aluminio con una pureza del $99,5 \%$, con un diámetro de $2 \mathrm{~mm}$ y un caudal de deposición de $2,7 \mathrm{~kg} / \mathrm{m}^{2}$ a $100 \mathrm{~A}$; el aluminio reemplaza la primera capa depositada en las 10 probetas anteriores, correspondiente a la capa de imprimante epóxico rico en zinc. Finalmente, se aplicó una capa de pintura poliaspártica de presentación. El granallado se realizó en la mañana y capa de rociado térmico y pintura se aplicó en la tarde del mismo día. Después de llevar a cabo los procesos de pintura, se procedió a exponer a las probetas en un ambiente salino. Para ello, se utilizó una cámara de niebla salina que se opera bajo la norma ASTM B117, la cual fue construida en la Universidad Tecnológica de Pereira y está certificada por el Organismo Nacional de Acreditación de Colombia (ONAC), bajo la norma NTC 1156; se realizaron inspecciones cada $24 \mathrm{~h}$ durante las primeras $1448 \mathrm{~h}$ de exposición, luego cada $168 \mathrm{~h}$ hasta llegar a 2256h. En cada inspección se obtuvieron imágenes para analizar cómo la corrosión afectaba las pinturas y los sustratos. Posteriormente, se realizaron ensayos de corrosión electroquímica, buscando conocer si el sistema de pintura y la capa de aluminio presentaban alguna protección contra la velocidad de corrosión.

Los ensayos de adherencia se realizaron por medio de ensayos de pull off bajo la norma ASTM D 4541, con el equipo Positest adhesión tester, utilizando adhesivo 3M referencia AC40, para conocer la adherencia de las pinturas y del rociado térmico. Este ensayo se realizó en tres etapas; antes de ingresar las probetas a la cámara de niebla salina, cuando tenían 1448 y $2256 \mathrm{~h}$ de oxidación, obteniendo así datos para analizar la variación de la adherencia a causa de la corrosión. También, en las tres etapas antes mencionadas, se obtuvieron imágenes en un Microscopio Electrónico de Barrido (MEB) marca Phenom Xpro. Posteriormente, se realizaron ensayos de resistencia a la polarización lineal para conocer el comportamiento de las muestras al ser sometidas a corrosión en un ambiente salino. El equipo que se utilizó fue un PotentiostatGalvanostat PG-Tekcorr 4.2. Este ensayo se realizó de acuerdo a la norma ASTM G59, y se utilizó una solución salina al $3,5 \%$ en peso. Se hicieron ensayos electroquímicos a las muestras en sus tres etapas, antes de ser sometidas al ambiente salino, cuando tenían $1448 \mathrm{~h}$ de exposición y finalmente con 2256h de exposición.

\section{Resultados y Discusión}

Después de 1448h de exposición en la cámara de niebla salina y no presentar signos de corrosión, en ninguno de los dos tipos de muestras (Bicapa y rociado térmico con poliaspártica), se procedió a rayar la mitad de las muestras siguiendo la norma ASTM B117 y nuevamente se ingresaron a la cámara, buscando acelerar el proceso de corrosión. A continuación en la Figura 1, se muestran las probetas con ambos sistemas de pintura en sus tres etapas de análisis, antes de ser expuestas al ambiente salino, después de $1448 \mathrm{~h}$ de exposición y luego de 2256h de exposición.

En la Figura 1, se observa el sistema de rociado térmico con aluminio y pintura poliaspártica (lado derecho); pintura bicapa (lado izquierdo). En la Figura 1a, se observa los sistemas antes de ser expuestos a la cámara de niebla salina, en donde el sistema bicapa tiene una mejor presentación. En la Figura 1b, se observa el sistema después de ser oxidada en cámara de niebla salina por 1448h; En la pintura bicapa se observan óxidos de hierro (herrumbre de color rojizo), los cuales forman una capa porosa, que no está fuertemente adherida a la 
superficie metálica y que permite la continuidad del proceso de oxidación, lo que conlleva a la pérdida la adherencia de la pintura.

En el lado derecho (rociado térmico más poliaspártica), no hay presencia de óxidos de hierro (herrumbre), ya que la capa de aluminio depositada por rociado térmico generó una capa de alúmina (color blanco), que tiene una estructura compacta y protege al substrato de la oxidación, evitando que la pintura pierda adherencia, lo que está corroborado con los ensayos de pull off (Tabla 1) y los potenciales de corrosión de los ensayos electroquímicos.

En la Figura 1c, se observa el sistema después de ser oxidada en cámara de niebla salina por $2256 \mathrm{~h}$ y tiene un comportamiento similar a la Figura $1 \mathrm{~b}$, pero a mayor escala.

a)

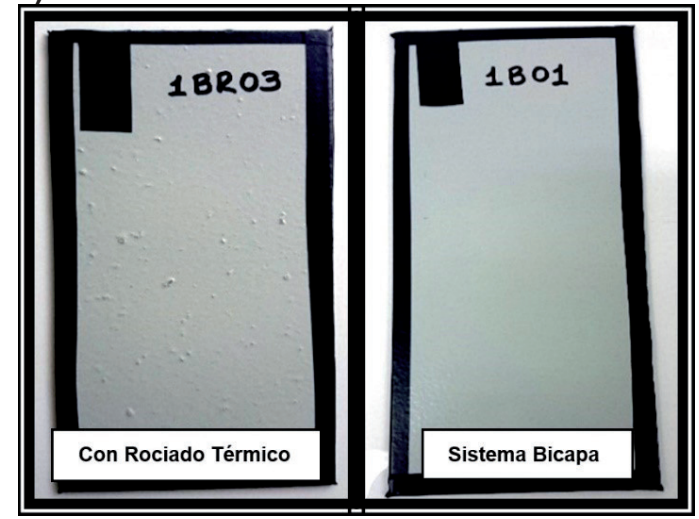

b)

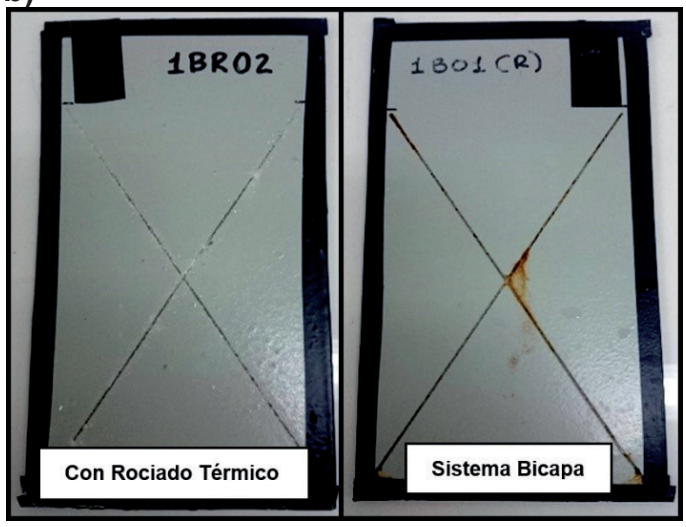

c)

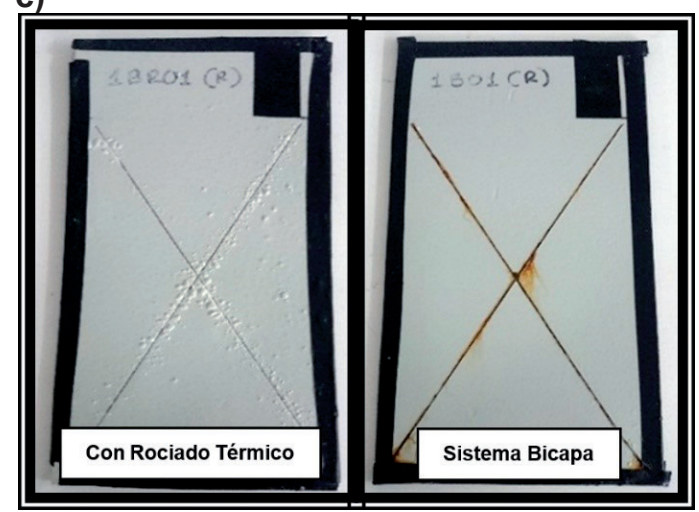

Figura 1. Probetas con rociado térmico más pintura poliaspártica y sistema bicapa sometidas a estudio. a) Probetas con y sin rociado térmico antes de ser ingresadas a la cámara de niebla salina. b) Probetas con rociado térmico más pintura poliaspártica y probeta con sistema bicapa, oxidadas en cámara salina después de 1448h. c) Probetas con rociado térmico más pintura poliaspártica y probeta con sistema bicapa, oxidadas en cámara salina después de 2256h. 
La adherencia de la pintura al substrato disminuyó muy poco en comparación con el sistema bicapa sin rociado térmico; también muestra que en la probeta sin rociado térmico el sustrato se está oxidando y formando óxidos de hierro, lo cual acelera el detrimento de las propiedades de la pintura, ya que la adherencia de la pintura disminuyó bastante en comparación con el sistema rociado térmico y pintura poliaspártica. Posteriormente se alcanzaron 2256h de exposición en cámara salina, para corroborar el comportamiento que se venía presentando en tiempos menores. En la Figura 1c, en el sistema con capa de aluminio, se observa la presencia de ampollas en algunas secciones de rayado, lo cual indica que el aluminio se oxidó, produciendo alúmina y por consiguiente protegiendo al sustrato de la oxidación; mientras que en la probeta sin rociado térmico, se hace aún más notoria la presencia de óxidos en el sustrato, no solo en la intersección de los rayados, sino también a lo largo de los mismos. Los ensayos de adherencia fueron realizados en las tres etapas antes mencionadas, arrojando los valores promedio que se muestran en la Tabla 1; donde se muestra en forma detallada para cada ensayo, valores de presión y de porcentaje de desprendimiento de las capas. Se puede apreciar que las presiones necesarias para el desprendimiento son más altas en las probetas que contaban con el sistema rociado térmico y pintura poliaspártica que en las que tenían sistema bicapa, lo que indica una mejor adherencia de la pintura poliaspártica a la capa de aluminio en comparación a la adherencia presentada entre las capas de imprimante epóxico rico en zinc y la pintura poliaspártica. Ahora bien, la anterior apreciación se ratifica al analizar los porcentajes de desprendimiento de material, ya que en el sistema rociado térmico y pintura poliaspártica son menores, induciendo esto hacia una mejor adherencia con respecto al área de análisis. Se observa que los porcentajes de desprendimiento aumentan a medida que avanzan las horas de oxidación, en ambos sistemas, siendo menor dicho avance en las probetas que poseen rociado térmico. En el sistema bicapa, el desprendimiento de los ensayos de adherencia ocurre en la interface imprimante epóxido rico en zinc y sustrato, quedando las dos capas de pintura sobre el dado del pull off; y en el sistema rociado térmico más pintura poliaspártica el desprendimiento ocurre en la interface aluminiopintura poliaspártica, quedando la pintura sobre el dado.

Tabla 1. Resultados de adherencia pull off (presión y porcentaje de desprendimiento).

\begin{tabular}{cccc}
\hline Sistema & Sin oxidar & $\begin{array}{c}\text { Oxidadas por } \\
\mathbf{1 4 4 8 h}\end{array}$ & $\begin{array}{c}\text { Oxidadas por } \\
\text { 2250h }\end{array}$ \\
\hline Bicapa & $891 \mathrm{psi}(2,37 \%)$ & 496psi $(10,12 \%)$ & $278 \mathrm{psi}(16,35 \%)$ \\
$\begin{array}{c}\text { Rociado térmico con } \\
\text { poliaspártica }\end{array}$ & 850psi $(1,34 \%)$ & $768 \mathrm{psi}(2,64 \%)$ & $723 \mathrm{psi}(6,56 \%)$ \\
\hline
\end{tabular}

En la Figura 2a, se observa por MEB la sección transversal de una probeta con sistema bicapa antes de ser expuesta al ambiente salino, en la cual se aprecia el substrato en los puntos (1, 2), en seguida, la primera capa de pintura que corresponde al imprimante epóxico rico en zinc, puntos $(3,4)$, luego, se encuentra la segunda capa de pintura, la cual es de naturaleza poliaspártica $(5,6)$, y por último en el punto (7) se encuentra la resina de la probeta. Según el análisis EDS, en promedio se encontró en los primeros dos puntos gran cantidad de hierro, más del $95 \%$, en los puntos 3 y 4 se encontró $11,8 \%$ de carbono, $70,7 \%$ de zinc y $17,5 \%$ de oxígeno, en los puntos 5 y 6 se encontró $22,8 \%$ de carbono, $39,2 \%$ de oxígeno, $7,5 \%$ de silicio, $5,3 \%$ de hierro y $25,2 \%$ de titanio. En esta imagen no se observan poros, ni vacíos, ni grietas, además presenta un buen anclaje de la pintura al substrato gracias a la rugosidad obtenida con el granallado, además de tener un espesor homogéneo presenta un buen contacto entre partículas de zinc y el sustrato, lo que permite al sustrato el beneficio de la protección catódica del zinc en el revestimiento.

En la Figura $2 b$, se aprecia la sección transversal por MEB, de una probeta con aluminio depositado por rociado térmico y con poliaspártica. Los puntos $(1,2,3)$ corresponden a la resina de la probeta, luego, en el punto (4) se encuentra la capa de pintura poliaspártica, en el punto (5) se ubica la capa de aluminio depositada por rociado térmico y finalmente el substrato en el punto (6). Según el análisis EDS, los primeros tres puntos corresponden a la resina de montaje de la muestra; en el punto 4 se encontró la misma composición de la pintura poliaspártica; en el 
punto 5 se encontró aluminio $89,2 \%$ y oxígeno 10,8\%. De esta imagen se puede inferir buena adherencia de la capa de aluminio al substrato, ya que no se aprecian muchas discontinuidades en la interface pintura substrato, además se observa un buen perfil de anclaje, gracias al granallado y la misma apreciación se puede hacer con respecto a la adherencia de la pintura en la capa de aluminio; esto es debido a que el rociado térmico copia la rugosidad de la superficie que ha sido granallada, generando así un buen anclaje de las capas posteriores de pintura.
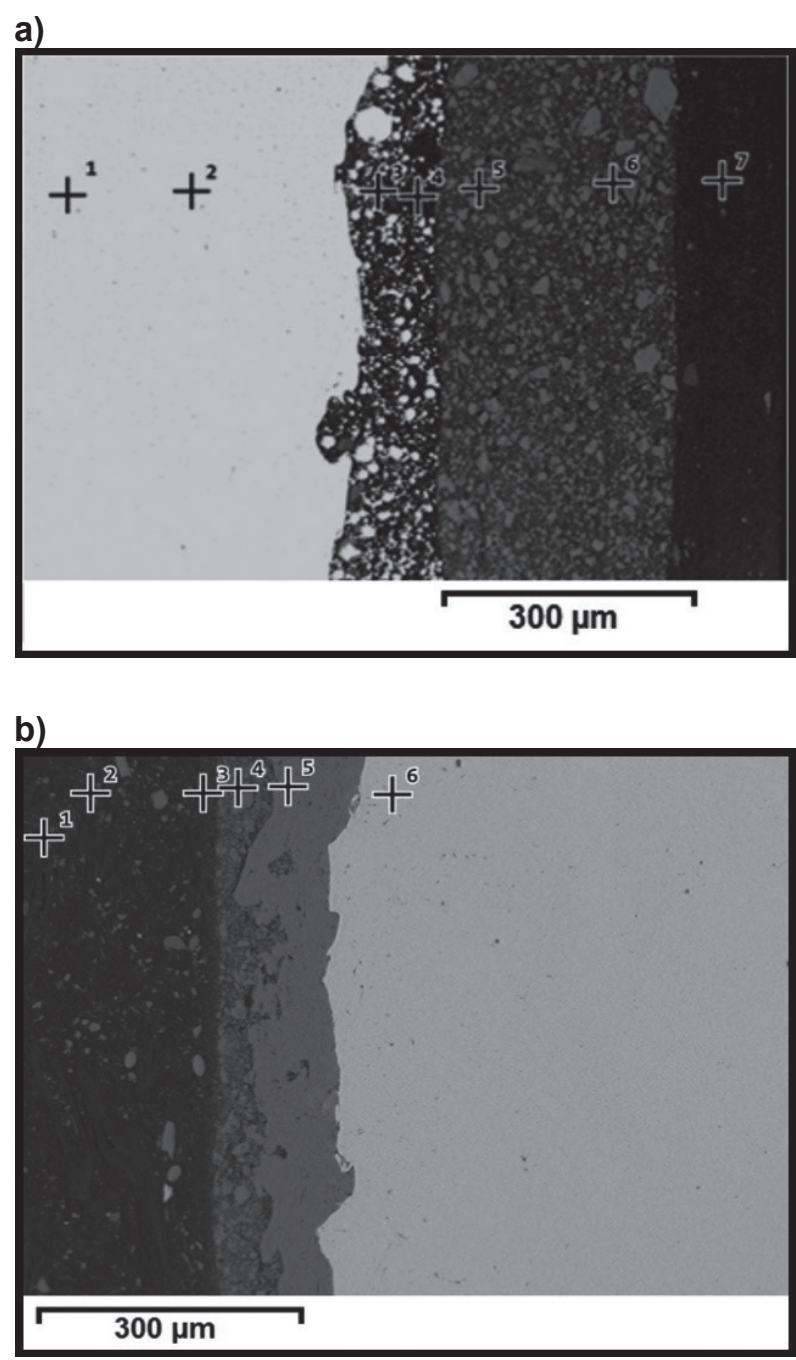

Figura 2. Sección transversal sistema bicapa y rociado térmico con poliaspártica antes de ser oxidados en cámara de niebla salina. a) Sección transversal sistema bicapa. b) Sección transversal sistema rociado térmico con poliaspártica.

Después de ser oxidadas las probetas en cámara de niebla salina durante $2256 \mathrm{~h}$, se realizaron análisis de microscopía MEB, con el fin de analizar las capas de pintura y de aluminio con respecto al tiempo de exposición. En la Figura 3a, se observa la sección transversal de una probeta recubierta con sistema bicapa, la cual se sometió a análisis EDS, indicando que en el número (1) la capa de pintura poliaspártica, contiene $26,6 \%$ de carbono, $44 \%$ de oxígeno, $15 \%$ de silicio, también hay presencia de hierro en un $6,6 \%$ y titanio en un $7,8 \%$. Luego, en los números $(2,3)$ se halla el imprimante epóxico rico en zinc, con presencia de carbono en un $54,8 \%$, zinc $30,8 \%$ y oxígeno en $14,4 \%$, se aprecia el aumento en el porcentaje de oxígeno lo que conlleva a inferir la presencia de óxidos de zinc, debido al proceso de oxidación en cámara salina. En el número (4), se aprecia una separación entre el sustrato y la primera capa de pintura, correspondiente a la capa de imprimante epóxico rico en zinc, dicha separación lleva a inferir una reducción en la adherencia de la pintura al sustrato, apreciación que se corrobora 
del ensayo de adherencia pull off (Tabla 1). En los números $(5,6)$, se observa el sustrato. El zinc realiza un par galvánico con el sustrato del acero, conllevando a una protección catódica, lo que implica una separación espacial de la reacción anódica y la catódica del proceso de corrosión, en donde la reacción anódica correspondiente a la disolución del zinc. Como resultado de la oxidación del zinc a zinc divalente, dos electrones son liberados y éstos fluyen a través de la película de revestimiento, para proteger al substrato del acero y evitar el ampollamiento del recubrimiento. En el sistema bicapa con rociado térmico, Figura $3 b$, en el número (1) se aprecia la resina de la probeta, en el número (2) está la capa de pintura poliaspártica, la cual presenta igual composición hallada en la muestra de la Figura 3a. Luego, en los puntos
$(3,4,5)$ está la capa del rociado térmico, con una composición de $89,2 \%$ de aluminio y $10,8 \%$ de oxígeno, por último en el número (6) está el sustrato. Esta figura muestra pocos cambios con respecto a las imágenes obtenidas antes de ser expuestas al ambiente salino, no se observa separaciones entre las capas de pintura y/o la capa de aluminio, conllevando esto a interpretar una continuidad en la adherencia de las capas, a excepción del sistema bicapa, en el cual hay claras señas de pérdida de adherencia. Los productos de corrosión del zinc y del aluminio se depositan en el recubrimiento bloqueando los poros y defectos, generando una barrera que reduce la penetración de la solución salina hacia el metal de base, que ayuda a pasivar la superficie del revestimiento, lo cual aumenta la vida útil del sistema de protección.

a)
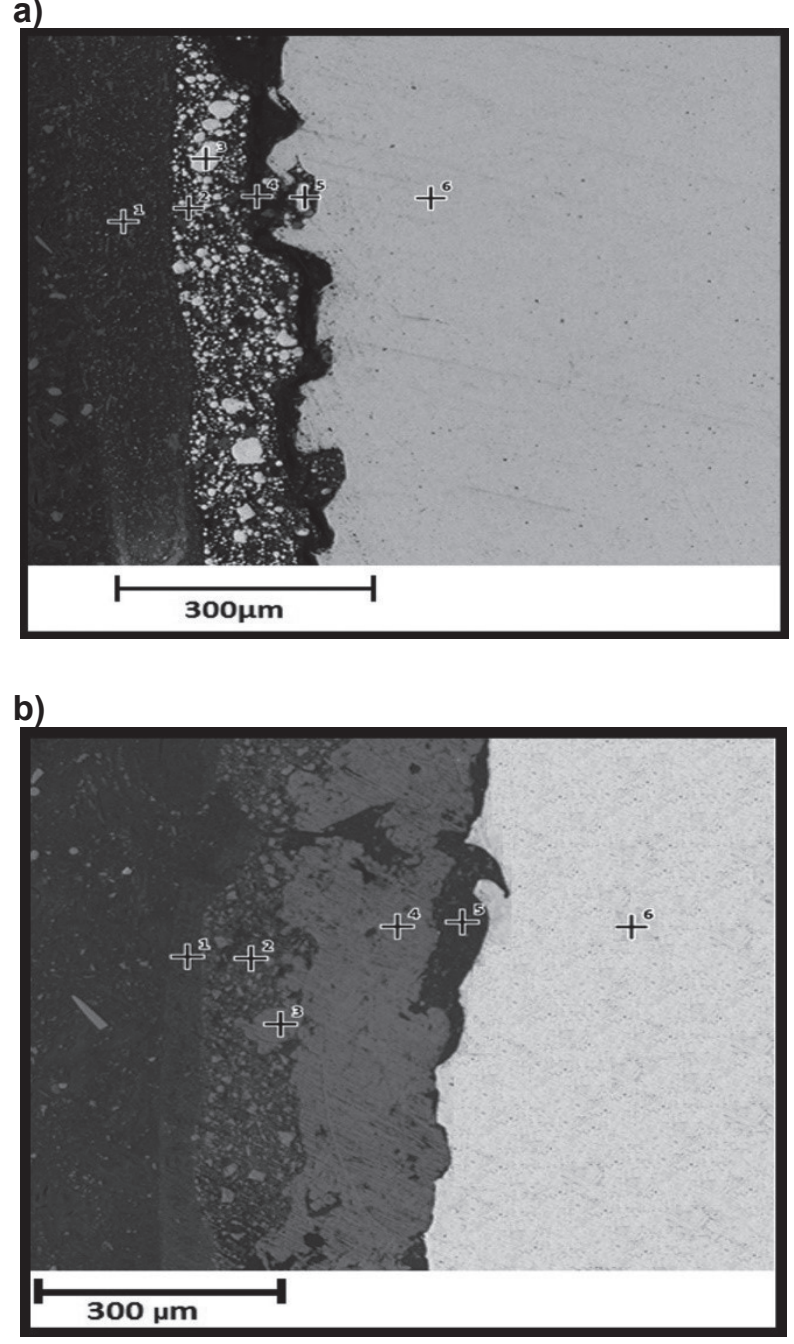

Figura 3. Sección transversal sistema bicapa y rociado térmico con pintura poliaspártica durante 2256h en cámara de niebla salina. a) Sección transversal sistema bicapa. b) Sección transversal sistema rociado térmico con pintura poliaspártica. 
En la Figura 4, se puede apreciar una imagen MEB de un área en particular, seleccionada de la línea de rayado de una probeta con rociado térmico y pintura poliaspártica, para conocer qué componentes se generan al exponer el material base al ambiente salino. Los resultados EDS entregaron la siguiente composición: $40,6 \%$ de aluminio, $20,5 \%$ de oxígeno, titanio en un $35,1 \%$ y carbono en $3,8 \%$. La capa de aluminio al oxidarse, generó una barrera protectora de alúmina de color blanco, que ayuda a aislar al material base del ambiente salino, evitando su deterioro.

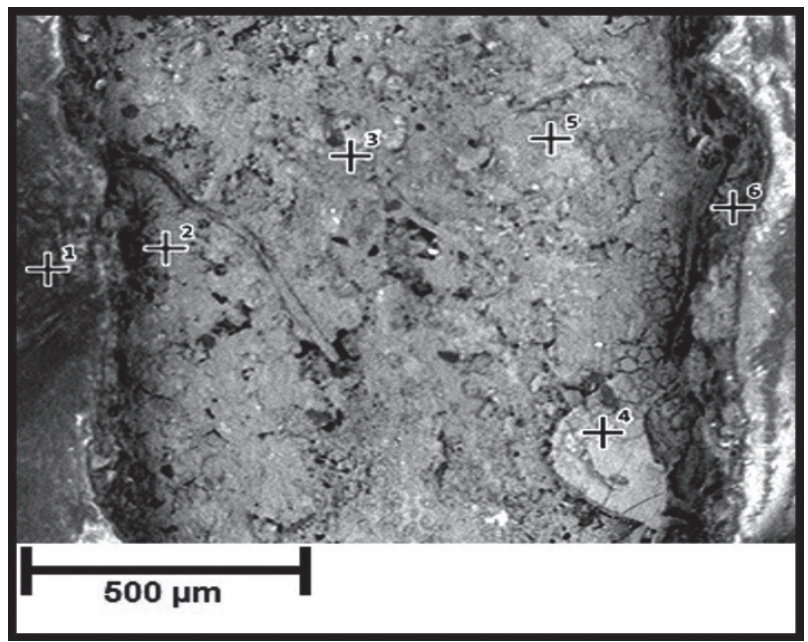

Figura 4. Imagen MEB de línea de rayado de la probeta con rociado térmico y pintura poliaspártica.

Para complementar este estudio se realizaron ensayos electroquímicos como curvas de Tafel y Resistencia a la Polarización Lineal (LPR), buscando valorar la cinética de reacción anódica y calcular la velocidad de corrosión de los dos tipos de sistemas de pintura (bicapa y rociado térmico con poliaspártica) al ser sometidos a un ambiente salino. Con las gráficas de resistencia a la polarización lineal y las constantes de Tafel se obtuvieron las velocidades de corrosión para los diferentes tiempos de exposición en el ambiente salino.

En la Figura 5 se observan las curvas de TAFEL para los sistemas bicapa y rociado térmico con pintura poliaspártica a 1448 y $2256 \mathrm{~h}$. Se identifican claramente los procesos anódicos y catódicos durante la polarización. Además no se observa una transición activo-pasivo, lo cual es típico para sistemas de corrosión bajo control difusional. Según la Figura 5 , se puede decir que se está presentando corrosión uniforme, debido a que no hay ninguna señal de pasividad o alguna discontinuidad en la gráfica que indiquen lo contrario. También se puede decir que el sistema está controlado cinemáticamente por la polarización de activación, ya que, tiene un comportamiento lineal (Tafeliano) del logaritmo de la corriente con respecto al potencial aplicado tanto en el sentido anódico como en el sentido catódico. La extrapolación de la zona lineal de Tafel permite determinar la densidad de corriente de intercambio y además se puede obtener el valor de los coeficientes de Tafel Ba y Bc con el valor del inverso de la pendiente de estas rectas, y con estos datos hallar la velocidad de corrosión como se puede apreciar en la Tabla 2. En esta tabla se aprecia que la velocidad de corrosión para el sistema rociado térmico y pintura poliaspártica tiene valores de velocidad de corrosión más bajos que para el sistema bicapa, con lo cual estaría mejor protegido el sustrato con el sistema rociado térmico y pintura poliaspártica.

El efecto de protección catódica empieza cuando el potencial de corrosión del sistema cambia a un valor más negativo (anódico) de $-0,80 \mathrm{~V}$ frente al electrodo de plata/cloruro de plata. Los potenciales de corrosión en esta gráfica están aproximadamente entre $-0,97$ y $-1,3 \mathrm{~V}$, lo que implica que hay una protección catódica del sustrato, tanto para el sistema bicapa como para el sistema rociado térmico más pintura poliaspártica. La velocidad de corrosión de los dos sistemas es muy baja, ya que hay una protección de los pigmentos de zinc y del aluminio; aunque hay un pequeño aumento del consumo de densidad de corriente para el sistema bicapa, siendo más alta la 
oxidación del zinc, lo puede conllevar a una pérdida de la adherencia de la pintura y un aumento en la velocidad de corrosión. La pérdida de adherencia fue corroborada con los ensayos de adherencia. Además, se observa que al aumentar el tiempo de exposición de los recubrimientos de 1148 a 2250h, el potencial de corrosión permanece por debajo del potencial de protección, por tal motivo la protección catódica sigue funcionando; esto muestra que los pigmentos de zinc y/o capa de aluminio no fueron totalmente consumidos y que el contacto galvánico no se perdió con el tiempo.

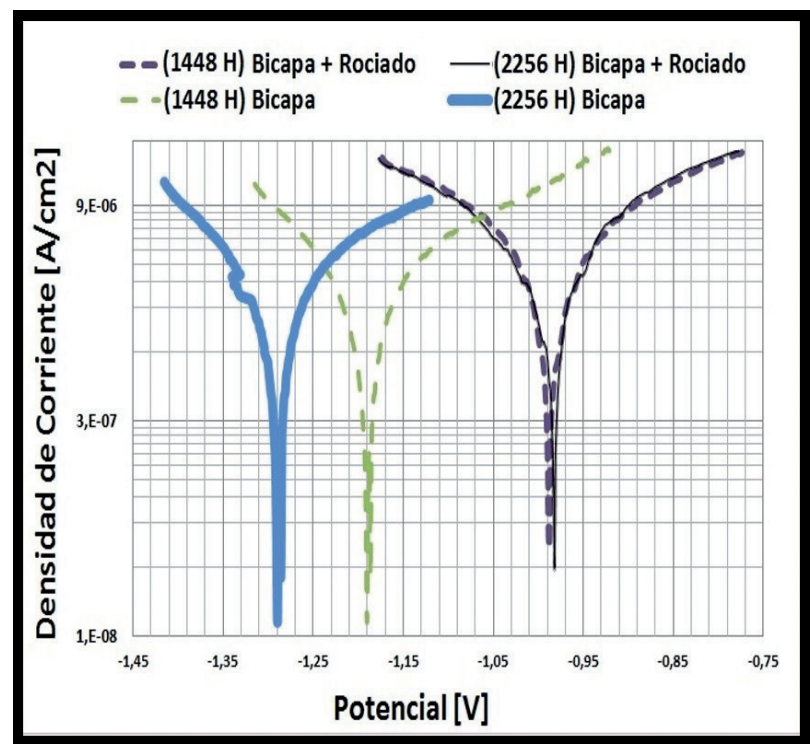

Figura 5. Curvas TAFEL para los sistemas bicapa y rociado térmico con poliaspártica.

Tabla 2. Velocidad de corrosión por curvas de Tafel y LPR en milésimas de pulgadas al año (mpy).

\begin{tabular}{ccccc}
\hline Sistema & & $\begin{array}{c}\text { Sin } \\
\text { oxidar }\end{array}$ & $\begin{array}{c}\text { Oxidadas } \\
\mathbf{1 4 4 8 h}\end{array}$ & $\begin{array}{c}\text { Oxidadas } \\
\mathbf{2 2 5 0 h}\end{array}$ \\
\hline \multirow{2}{*}{ Bicapa } & Tafel & 0,00 & 0,09353 & 0,09746 \\
& LPR & 0,00 & & \\
\hline Rociado térmico & Tafel & 0,00 & 0,08247 & 0,08647 \\
con poliaspártica & LPR & 0,00 & & \\
\hline
\end{tabular}

La resistencia a la polarización lineal implementa pequeñas polarizaciones cerca de $10 \mathrm{mV}$ en la probeta de prueba en ambos sentidos y recopila la corriente resultante como se observa en la Figura 6. En esta figura, se aprecian las líneas de resistencia de polarización lineal, para los dos sistemas de pintura, luego de ser expuestas al ambiente salino por 1448 y $2256 \mathrm{~h}$; en dicha figura no se incluyen las muestras antes de ser ingresadas a la cámara de niebla salina, debido a que éstas, se comportaron como aislantes al momento de realizar los ensayos, por tal motivo se podría decir que la velocidad de corrosión para esta últimas probetas es muy pequeña o que no presentan corrosión, ya que no hay un electrolito conductor que cierre el circuito, ya que para que se dé la corrosión se necesita de un ánodo, un cátodo y un electrólito conductor que cierre el circuito.

La pintura en un inicio actúa como barrera (aislante) y no permite el contacto del electrolito con el sustrato, evitando que se corroa el sustrato. Se puede apreciar que las muestras sin la capa de aluminio depositada por el rociado térmico, presentan una pendiente mayor, la cual se va en aumento con el tiempo de exposición, lo que lleva a intuir que el rociado térmico de aluminio proporciona protección contra la corrosión para aceros al carbono, ya que la pendiente está relacionada directamente con la velocidad de corrosión. 


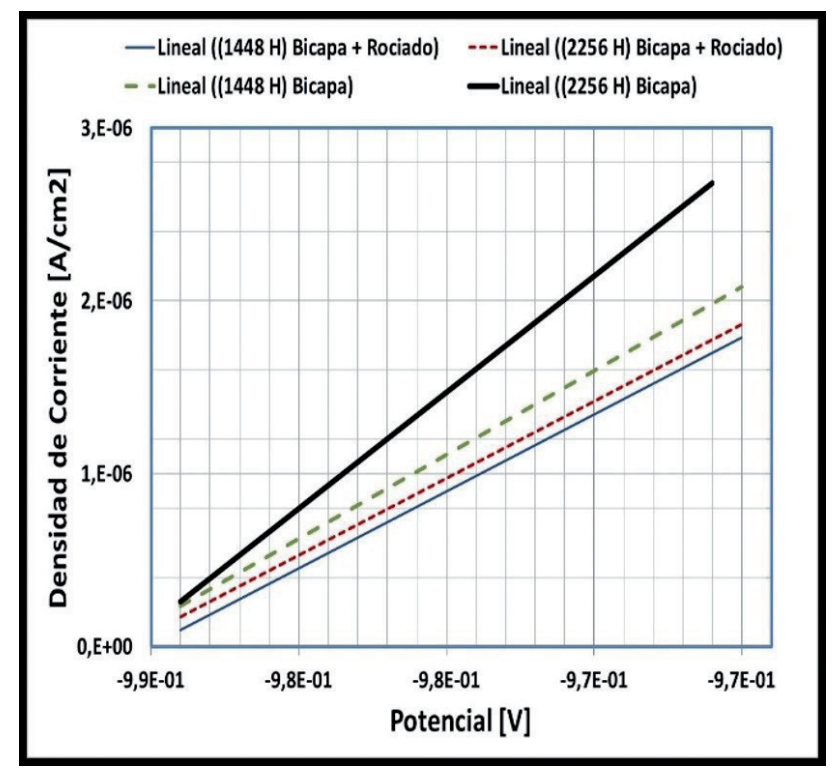

Figura 6. Líneas de LPR de los sistemas bicapa y rociado térmico con poliaspártica.

\section{Conclusiones}

Las probetas con el sistema rociado térmico de aluminio con poliaspártica, proporcionaron una mejor protección del sustrato contra la corrosión en ambientes salinos en comparación con el sistema de pinturas bicapa, aun cuando las muestras fueron sometidas a rayado después de $1448 \mathrm{~h}$ de oxidación para acelerar el proceso de corrosión; debido a que se obtiene una protección galvánica y no deja formar los óxidos de hierro que dan mal aspecto visual a la pintura.

Las probetas con el sistema de pintura bicapa y sin rociado térmico, deben cumplir con una vida útil en cámara de niebla salina de mínimo 1448h. Cabe destacar que ellas no fallaron antes de ese tiempo, ya que solo se observó un punto minúsculo de oxidación en un poro de la pintura después de 1320h de exposición.

Al momento de ingresar las probetas a la cámara de niebla salina, los indicadores de adherencia para el sistema bicapa y rociado térmico con pintura poliaspártica fueron muy similares. Luego de $1448 \mathrm{~h}$ de oxidación los indicadores de adherencia bajaron considerablemente en el sistema bicapa, mientras que en el sistema bicapa con rociado térmico el cambio fue mínimo, además las imágenes MEB muestran una buena adherencia del rociado térmico al sustrato y de la pintura al rociado térmico, ya que no se aprecian grietas ni separaciones entre las capas.

\section{Referencias bibliográficas}

[1] Ahnia F, Demri B. Evaluation of aluminum coatings in simulated marine environment. Surf. Coat. Technol. 2013;220:232-6.

[2] Regina MH, Pombo R, Schereiner SC, Wido $\mathrm{H}$, Calixto $\mathrm{A}$. Comparison of aluminum coatings deposited by flame spray and by electric arc spray. Surf. Coat. Technol. 2007;202(1):172-9.

[3] Li HY, Duan JY, Wei DD. Comparison on corrosion behaviour of arc sprayed and zinc-rich coatings. Surf. Coat. Technol. 2013;235:259-66.

[4] Muhamad HA, Nor HS, Abasa SK, Nik NR, Noriyati MS. Performance and Microstructure Analysis of $99.5 \%$ Aluminium Coating by Thermal Arc Spray Technique. Procedia Eng. 2013;68:558-65.

[5] Bolelli G, Candeli A, Koivuluoto H, Lusvarghi L, Manfredini T, Vuoristo P. Microstructure-based thermo- mechanical modelling of thermal spray coatings. Mater Des. 2015;73:20-34.

[6] Perez A, Billard C, Rébéré C, Berziou S, Touzain $S$, Creus J. Influence of metallurgical states on the corrosion behavior of Al-Zn PVD coating in saline solution. Corros Sci. 2013;74:240-9.

[7] Marulanda JL, Tristancho JL, Cañas A. Protección contra la corrosión en sales fundidas de un acero hot rolled, en el rango de temperaturas de $400^{\circ} \mathrm{C}$ y $600^{\circ} \mathrm{C}$, recubierto por rociado térmico con acero inoxidable 312 . Dyna. 2009;76( 160):229-35. 
[8] Cinca N, Camello CR, Guilemany JM. An overview of intermetallics research and application: Status of thermal spray coatings. J Mater Res Technol. 2013;2(1):75-86.

[9] Matthew K, Hedges A, Newbery P, Grant P. Characterization of electric arc spray formed Ni superalloy IN718. Mater Sci Eng: A. 2002; 326(1):79-91.

[10] Jandin G, Liao H, Feng ZQ, Coddet C. Correlations between operating conditions, microstructure and mechanical properties of twin wire arc sprayed steel coatings. Mater Sci Eng: A. 2003;349(1-2):298-305.

[11] Barletta AM, Gisario A, Puopolo M, Vesco S. Scratch, wear and corrosion resistant organic inorganic hybrid materials for metals protection and barrier. Mater Des. 2015;69:130-40.

[12] Chakravarthy D, Barve DN, Patil DS, Mishra P, Prasad CS, Rout RK. Development and characterization of single wire arc plasma sprayed coating of nickel on carbon blocks and alumina tube substrates. Surf. Coat. Technol. 2007;202:325-30.

[13] Sá Brito VRS, Bastos IN, Costa HRM. Corrosion resistance and characterization of metallic coatings deposited by thermal spray on carbon steel. Mater Des. 2012;41:282-8.

[14] Newbery AP, Grant PS. Oxidation during electric arc spray forming of steel. J Mater Process Tecnhol. 2006;178(1-3):259-69.

[15] Schaefer K, Miszczyk A. Improvement of electrochemical action of zinc-rich paints by addition of nanoparticulate zinc. Corros Sci. 2013;66:380-91.

[16] Akbarinezhad E, Ebrahimi M, Sharif F, Ghanbarzadeh A. Evaluating protection performance of zinc rich epoxy paints modifiedwith polyaniline and polyanilineclay nanocomposite. Prog Org Coat. 2014; 77:1299-308. 